\title{
La ley fundamental en su sesenta aniversario*
}

\author{
Michael Sachs** \\ Catedrático de Derecho Constitucional \\ Universidad de Colonia (Alemania)
}

Recibido: 22.02 .2011

Aceptado: 18.03 .2011

Resumen. El importante tiempo de vigencia de la Ley Fundamental alemana de 1949 permite hacer una mirada retrospectiva para valorar cómo ha ido desplegando progresivamente su realidad normativa y su eficacia. En este contexto, es particularmente interesante analizar el desarrollo de cuestiones como, por ejemplo, el tema del federalismo, aspectos relativos a la hacienda pública, distribución de competencias, organización del Estado, reforzamiento del principio democrático y garantía de los derechos fundamentales y constitucionales. Este tema cobra además mayor interés si tenemos en cuenta que, en ciertos casos, para la adaptación de la Constitución alemana a las necesidades que el paso del tiempo ha ido imponiendo se han ido acometiendo sucesivas y peculiares reformas de la misma. Este trabajo es una síntesis concisa pero detallada de las fases más importantes de esa evolución.

Palabras clave. Ley Fundamental alemana, reforma de la Constitución, federalismo, reforzamiento constitucional.

\begin{abstract}
The important validity of the German Constitutional Law of 1949 allow to do a gaze with hindsight in order to appreciate how has been clarifying progressively its regulations and its effectiveness. In this context, it's particularly interesting to analyze the development of questions like, for example, the federalism subject, aspects relating to the Public Treasury, power's distribution, the State organization, the reinforcement of the democratic principle and the warranty of the fundamental and constitutional rights. This subject becomes more interest if we take account of the adaptation of the German Constitution eventually to the successive and particular reforms of it that it has been undertaken. This work is a brief summary but detailed of the more important phases of that evolution.
\end{abstract}

Key words. Basic Law for the Federal Republic of Germany, Constitution Reform, Federalism, framework, constitutional strengthening.

SUMARIO. I. Introducción. II. La evolución de la Ley Fundamental desde 1999. 1. Modificaciones de preceptos individuales. 2. La revisión

\footnotetext{
* El original de este trabajo puede encontrarse en Michael SACHS, «Das Grundgesetz in seinem sechsten Jahrzehnt», en Neue Juristische Wochenschrift, Vol. 62, n. ${ }^{\circ}$ 21, 2009, pp. 1441-1449.

** Traducido por Alberto Oehling de los Reyes. Profesor ayudante de Derecho Constitucional de la Universidad de las Islas Baleares.
} 
de la Ley Fundamental con relación a la reforma del federalismo. a) Origen. b) Las relaciones financieras del Estado Federal. c) La distribución de competencias legislativas. d) Necesidad de autorización de leyes federales. III. Tendencias en la doctrina del Tribunal Constitucional Federal desde 1999. 1. Resoluciones relativas a la organización jurídica del Estado. a) Principios estructurales del Estado. b) Partidos políticos. d) Funciones del Estado. 2. Resoluciones relativas a los derechos fundamentales. a) Teoría general de los derechos fundamentales. b) Derechos fundamentales individuales. 3. Las resoluciones con efecto supranacional. a) Derecho de la Unión Europea. b) El Convenio Europeo de los Derechos Humanos. c) Intervenciones militares en el extranjero. d) Problemas migratorios y cuestiones en relación a la extradición. 4. Los problemas con la libertad religiosa. 5. Libertad y seguridad. IV. Conclusión.

\section{Introducción}

El 23 de mayo de 1949 entraría en vigor la Ley Fundamental ${ }^{1}$, si bien, por entonces, solamente tendría vigencia en las zonas ocupadas del Oeste, de acuerdo a lo que establecía el artículo 23 de la Ley Fundamental, siendo una Constitución bajo reserva de sustitución en el caso de que se alcanzara la reunificación, en los términos del artículo 146 de la Ley Fundamental. Sin embargo, aún cuando esta solución provisional ha tenido validez durante sesenta años, la sustitución de la Ley Fundamental por otra Constitución ${ }^{2}$ es ya un tema agotado actualmente.

Durante este tiempo la Ley Fundamental ha experimentado cincuenta y cuatro modificaciones de cierta entidad. La primera década se caracterizaría por las reformas en aspectos de defensa ${ }^{3}$, mientras que los años sesenta serían muestra del compromiso por la recepción de conceptos de previsión social ${ }^{4}$, que conllevarían además una nueva Constitución financiera y presupuestaria $^{5}$. Los años setenta, por otra parte, no tendrían logros comparables ${ }^{6}$. En los

${ }^{1}$ Para más detalles, haciendo hincapié en el carácter provisional de la nueva Constitución, véase Michael SACHS, en el mismo autor (edit.), Grundgesetz, 5. edic. 2009, nota al margen n. ${ }^{\circ} 15$; HUBER, Ibídem, «Präambel», nota al margen $n .^{\circ} 5$.

${ }^{2}$ Respecto a las posibilidades del artículo 146 de la Ley Fundamental (nueva redacción), véase, HUBER, en SACHS (edit.), Grundgesetz, «Art. 146», cit., nota al margen n. . 3, 7 y ss.; SACHS, Michael, Juristische Schulung 1991, pp. 985 y ss.

${ }^{3}$ Véase la Ley de complementación (Gesetze für Ergänzung des GG) de la Ley Fundamental de 26 de marzo de 1954, BGB1. I, p. 581, y de 12 de mayo de 1969, BGB1. I, p. 357.

${ }^{4}$ Véase la decimoséptima Ley de complementación de 24 de junio de 1968, BGBl. I, p. 709.

${ }^{5}$ Compárese la decimoquinta y vigésima Ley de reforma de la Ley Fundamental de 8 de junio de 1967, BGB1. I, p. 581, y de 12 de mayo de 1969, BGB1. I, p. 357.

${ }^{6}$ Compárese la propuesta de la Comisión Parlamentaria para la reforma constitucional (Enquête-Kommision Verfassungsreform), Bundestagsdrucksache 7/5924. 
años ochenta no se operaría en la Ley Fundamental casi ningún cambio hasta 1989, etapa en la que, estando la anhelada unidad alemana ya a la vuelta de la esquina, también marcaría -junto con la constitucionalización del proceso de unificación europea ${ }^{7}-$ los años noventa con la discusión sobre una nueva Constitución para toda Alemania ${ }^{8}$, y eso aún cuando las modificaciones constitucionales derivadas del Tratado de Reunificación ${ }^{9}$ solamente habían llevado a reformas notables de la Ley Fundamental en $1994{ }^{10}$. A partir de ahí la evolución de la Ley Fundamental desde 1999 debe tratarse con mayor profundidad (epígrafe 2).

Qué es lo que significa realmente la Ley Fundamental se determina también indefectiblemente a través de la praxis de su aplicación, sobre todo a través de la judicatura del Tribunal Constitucional Federal. Sólo en los últimos diez años, nos encontramos con nada más y nada menos que veinte volúmenes de resoluciones de la Sala ${ }^{11}$. La selección de casos y progresos a describir es necesariamente muy limitada, pero debería ayudar a determinar en qué punto se encuentra la Ley Fundamental tras sesenta años (epígrafe 3).

\section{La evolución de la Ley Fundamental desde 1999}

\section{Modificaciones de preceptos individuales}

Desde 1999 las normas promulgadas en orden a la modificación de la Ley Fundamental estaban destinadas, sin excepción, a delimitar y perfilar preceptos individuales muy diferenciados. Las posibles interrelaciones en cuanto al contenido solo se encuentran en aspectos límite, si bien la mayoría de las revisiones presentan puntos en común, sobre todo en cuestiones de desarrollo y complementación.

Así, se operarían dos modificaciones, al menos parcialmente, como vías de desarrollo del Derecho penal internacional y de la jurisdicción penal internacional $^{12}$. Susodichas reformas, afectarían, por un lado, a la cuadragésima séptima Ley de Reforma (47. ÄndG) ${ }^{13}$, referida a la reserva legal relativa a la prohibición de extradición determinada en el nuevo artículo 16.2 de la Ley Fundamental, y, por otro lado, a la quincuagésima primera Ley de Reforma

\footnotetext{
${ }^{7}$ Compárese, en el contexto del Tratado de Maastricht, la Ley de Reforma de la Ley Fundamental de 21 de diciembre de 1992, BGB1. I, p. 2086.

${ }^{8}$ Compárese HUBER, «Art. 146», en SACHS, Michael (edit.), Grundgesetz, cit., nota al margen $n .^{\circ} 4$ y ss.

${ }^{9}$ Ibídem, «Art. 4».

${ }^{10}$ Véase la Ley de reforma de la Ley Fundamental (Artículos 3, 20 a, 28, 29, 72, 74, 75, $76,77,80,87,93,118$ a, y 125 a).

${ }^{11}$ Desde la B VerfGE 100, 313.

${ }^{12}$ Compárese KOKOTT, «Art. 16», en SACHS, Michael (edit.), Grundgesetz, cit., nota al margen $n .^{\circ} 44$ y 50; DETTERBECK, Ibídem, «Art. 96», nota al margen n. ${ }^{\circ} 18$.

${ }^{13}$ Ley de reforma de la Ley Fundamental (Artículo 16) de 29.11.2000, BGBl I, p.. 1633.
} 
(51. ÄndG $)^{14}$, referida a la ampliación de las posibilidades mediatas de la jurisdicción del Poder Judicial federal (Bundesgerichtsbarkeit), de acuerdo a la nueva redacción del artículo 96.5 de la Ley Fundamental.

Varias de las reformas constitucionales están en conexión con el proceso de unificación europeo. En este orden, se materializó la modificación del propio artículo 16.2 de la Ley Fundamental en relación con las posibilidades de extradición de una persona a un Estado miembro en consonancia con la Decisión marco relativa a la orden de detención europea ${ }^{15} \mathrm{y}$, paralelamente, se perfilaron los procedimientos de entrega entre Estados miembros ${ }^{16}$. Por otra parte, el artículo 12.a 4 de la Ley Fundamental debe su transformación a una decisión del Tribunal de Justicia Europeo, que ha rechazado ciertas limitaciones en caso de prestación de servicios voluntarios de mujeres en la Bundeswehr $r^{17}$. Se comprende que la anterior redacción en orden a la delimitación de sus funciones pero con exclusión por fuerza de la mujer del servicio armado dentro del servicio en las Fuerzas Armadas, de conformidad con el artículo 12.a 4 de la Ley Fundamental ${ }^{18}$, tenía que ser modificada, cuando menos a efectos de dotarle de una mayor precisión ${ }^{19}$. El proceso de unificación europeo ha dado lugar también a una reforma adicional de la Ley Fundamental ${ }^{20}$ destinada a la asunción de ciertas previsiones en relación al derecho de colaboración de los Parlamentos de los Estados miembros ${ }^{21}$, una vez entre en vigor el Tratado de Lisboa ${ }^{22}$. Finalmente, hay, además, que decir que se ha ido caminando hacia una Europa unida de la mano de importantes modificaciones para la reforma del federalismo ${ }^{23}$ (véase el punto 2). Por ejemplo, se ha pres-

${ }^{14}$ Ley de reforma de la Ley Fundamental (Artículo 96) de 26.7.2002, BGB1 I, p.. 2863.

${ }^{15}$ Diario Oficial L 190/1 v. 18.7. 2002, S. 1

${ }^{16}$ Sobre ello, por ejemplo, KOKOTT, en SACHS, Michael (edit.), Grundgesetz, cit., nota al margen n. ${ }^{\circ} 44$ y 45 . Con relación a otros desarrollos en conexión con la orden de detención europea, véase, la nota a pie del presente trabajo número 149.

${ }^{17}$ STJCE, de 11 de enero de 2000, C-285/98 , caso Tanja Kreil. Véase, también, en Neue Juristische Wochenschrift 2000, pp. 497 y ss.

${ }^{18}$ En detalle, véase, SACHS, Michael, en STERN, Klaus, Das Staatsrecht der Bundesrepublik Deutschland, Vol. IV/1, 2006, pp. 1052 y ss.

${ }^{19}$ Así, KOKOTT, «Art. 12.a», en SACHS, Michael (edit.), Grundgesetz, cit., nota al margen $\mathrm{n} .^{\circ} 16$.

${ }^{20}$ Ley de reforma de la Ley Fundamental (Artículos 23, 45 y 93) de 8.10.2008, BGB1. I, p. 1926.

${ }^{21}$ Compárese Bundestagsdrucksache 16/8488 y 16/8489. Sobre ello, por ejemplo, STREINZ, «Art. 23», en SACHS, Michael (edit.), Grundgesetz, cit., nota al margen n.o 123 y 125; MAGIERA, «Art. 45», Ibídem., nota al margen nº . 8; STURM, «Art. 93», Ibídem., nota al margen $n{ }^{\circ} 54$ y nota a pie $101 \mathrm{a}$.

${ }^{22}$ Ley de reforma de la Ley Fundamental (Artículo 2) de 8.10.2008, BGBl. I, p. 1926.

${ }^{23}$ Ley de reforma de la Ley Fundamental (Artículos 22, 23, 33, 52, 72, 73, 74, 74a, 75, $84,85,87$ c, 91a, 91b, 93, 98, 104a, 104 b, 105, 107, 109, 125a, 125b, 125c, 143c) de 28.8.2006, BGBl. I, p. 2034. 
crito la cesión de ciertas prerrogativas de la República Federal de Alemania, en cuanto Estado miembro de la Unión Europea, a un representante de los Länder designado por el Bundesrat. Posibilidad que se prevé ahora forzosamente en orden a una serie tasada de competencias (artículo 23.6 de la Ley Fundamental) ${ }^{24}$. Además, por otra parte, el nuevo epígrafe 6 del artículo 104 de la Ley Fundamental aclara también la desde siempre dificultosa cuestión de cómo se han de distribuir -entre la Federación y los Länder - las cargas o compensaciones ante una infracción por parte de Alemania de las obligaciones supranacionales o de Derecho internacional ${ }^{25}$.

Dentro de las leyes de modificación permanentes encontramos, ya en el contexto de la reforma del federalismo, la referida al artículo 108 de la Ley Fundamental $^{26}$. A efectos de una renovación de la Administración financiera de la Federación y los Länder ${ }^{27}$, los denominados órganos ejecutivos intermedios (Mittelbehörden) se dedican ahora, no ya como una mera posibilidad dentro de sus funciones sino de forma directa ${ }^{28}$, a la realización de criterios de eficiencia de la Administración ${ }^{29}$. Igualmente, hay que decir que la Ley Fundamental ha necesitado, asimismo, de una modificación para la implementación del Impuesto de vehículos (Kraftfahrzeugsteuer) en la Federación $^{30}$. Finalmente hay que citar también la adición, en 1994, del artículo 20.a de la Ley Fundamental, relativo a la protección del medio ambiente y a la protección de animales ${ }^{31}$.

\section{La revisión de la Ley Fundamental con relación a la reforma del federalismo}

a) Origen

La reforma del federalismo de 2006 es una de las modificaciones más amplias que, en general, ha experimentado la Ley Fundamental. Esta revisión ha afectado a un total de veinticinco preceptos, entre artículos modificados,

\footnotetext{
${ }^{24}$ Véase STREINZ, «Art. 23», en SACHS, Michael (edit.), Grundgesetz, cit., nota al margen $\mathrm{n}^{\circ} 114$.

${ }^{25}$ SIEKMANN, «Art. 104.a», en SACHS, Michael (edit.), Grundgesetz, cit., nota al margen . $^{\circ} 55$ y ss.

${ }^{26}$ Ley de reforma de la Ley Fundamental (Artículo 108) de 26.11.2001, BGB1. I, p. 3219.

${ }^{27}$ Hasta entonces, en pro de una norma concluyente, SEER, «Art. 108», en Bonner Komm. zum $G G$, (1999), notas al margen n. ${ }^{\circ}$ 66, 82. Otros datos en SIEKMANN, «Art. 108», en SACHS, Michael (edit.), Grundgesetz, cit., nota al margen n. ${ }^{\circ} 15$.

${ }^{28}$ Compárese SIEKMANN, «Art. 108», en SACHS, Michael (edit.), Grundgesetz, cit., notas al margen n. ${ }^{\circ} 15,17,20$ y 26.

${ }^{29}$ En especial, con relación a los pequeños Länder, pero también a nivel de la Federación, véase, Bundestagsdrucksache 14/6144, p. 6.

${ }^{30}$ Ley de reforma de la Ley Fundamental (Artículos 106, 106b, 107, 108), de 19.3.2009, BGB1. I, p. 606.

${ }^{31}$ Véase, así, MURSWIEK, «Art. 20a», en SACHS, Michael (edit.), Grundgesetz, cit., notas al margen n. ${ }^{\circ} 11,15$ y ss., $31,31 \mathrm{~b}, 36 \mathrm{a}, 51^{\mathrm{a}}$ y ss., 55 y ss., $63,68 \mathrm{~b}$ y ss., 72 y ss.
} 
suprimidos o de nueva creación. El fortalecimiento de las estructuras federales $^{32}$ había figurado, por así decir, en el orden del día desde la Reunificación ${ }^{33}$, de modo que, ya en 1994, tras la unidad, se volvería a pensar en una gran reforma constitucional ${ }^{34}$.

Empero, aunque la modernización del ordenamiento estatal se veía como necesaria por encima de los intereses de los propios partidos, se malograría finalmente una reforma en la décimo-quinta legislatura. Ahora bien, en 2006, este fracaso se atenuaría ya que, en el marco de una coalición política, podrían ser aprobados los trabajos preparatorios a tal efecto, necesarios para acometer una primera fase de reforma del federalismo ${ }^{35} \mathrm{y}$ dirigidos a mejorar la capacidad de decisión de la Federación y los Länder, clarificar la clasificación de las responsabilidades y realizar un aumento de la eficiencia en la ejecución de competencias ${ }^{36}$.

\section{b) Las relaciones financieras del Estado Federal}

Las cuestiones más peliagudas de las relaciones financieras se regularían inicialmente de forma parcial ${ }^{37}$. Principalmente, por un lado, se revisarían las posibilidades de financiación mixta del artículo 91.a y b de la Ley Fundamental y se agravarían los requisitos para las ayudas financieras de la Federación para inversiones de los Länder a través del nuevo artículo 104.b de la Ley Fundamental ${ }^{38}$. Por otro lado, la promulgación de las leyes de mínimos de la Federación, que concierne a las cargas de gasto de los Länder, pasarían a depender de una aprobación del Bundesrat, de acuerdo al artículo 104.a 4 de la Ley Fundamental. En otro orden de cosas, también es significativa la prohibición de transferencia de obligaciones o funciones por ley federal a los municipios prescrita en los artículos 84.1 y 85.1 de la Ley Fundamental ${ }^{39}$.

${ }^{32}$ En especial en cuanto a las competencias legislativas y la participación del Bundesrat. Más detalles en SCHMALENBACH, Föderalismus und Unitarismus in der Bundesrepublik Deutschland, 1998.

${ }^{33}$ Véase el artículo 5 del Tratado de Reunificación de 31 de agosto de 1990.

${ }^{34}$ Compárese con el Informe de la Comisión Constitiucional Conjunta, Bundestagsdrucksache 12/6000, pp. 30 y ss, el Segundo Capítulo «Bund und Länder». Para más detalles, véanse, también, las referencias a la distribución competencial.

${ }^{35}$ Véase un compendio de los antecedentes en Bundestagsdrucksache 16/813, p. 7.

${ }^{36}$ Bundestagsdrucksache 16/812, p. 1. Para más datos, véase SACHS, Michael «Art. 20», en, el mismo autor (edit.), Grundgesetz, cit., nota al margen n. ${ }^{\circ} 58 \mathrm{a}$.

${ }^{37}$ Para una visión global de aspectos jurídico constitucionales en materia financiera, véase, por ejemplo, SIEKMANN, «Art. 104a», en SACHS, Michael (edit.), Grundgesetz, cit., notas al margen . $^{\circ} 37$ y ss.

${ }^{38} \mathrm{Al}$ respecto, ténganse en cuenta las regulaciones transitorias de los artículos $125 . \mathrm{c}$ I y II y 143.c de la Ley Fundamental.

${ }^{39}$ DITTMANN, «Art. 84», en SACHS, Michael (edit.), Grundgesetz, cit., nota al margen n. ${ }^{\circ} 13$. 
Y para seguir la tendencia de reforma se designaría, a finales del 2006, una Comisión conjunta del Bundestag ${ }^{40}$ y el Bundesrat ${ }^{41}$ para la modernización de las relaciones financieras entre la Federación y los Länder, la cual propondría reformar y, en su caso, intercalar los artículos 109, 109 a, 115, así como 143 .d de la Ley Fundamental ${ }^{42}$. Ahora bien, si tal propuesta, que incluye la posibilidad de endeudamiento público, se acabará implantando plenamente es algo que todavía no podemos saber.

\section{c) La distribución de competencias legislativas}

La mayor reforma con relación a la distribución de competencias legislativas entre la Federación y los Länder, desde la existencia de la Ley Fundamental, tendría lugar principalmente en 2006. En las primeras décadas de la Ley Fundamental la posibilidad de implementación y ampliación del título competencial vigente de la Federación, derivada de la «cláusula de necesidad» (Bedürfnisklausel) del artículo 72.2 de la Ley Fundamental en su redacción antigua*, había tenido, también con cierta renuencia del Tribunal Constitucional Federal ${ }^{43}$, una aplicación restrictiva, pero, no obstante, llevó a un progresivo socavamiento ${ }^{44}$ del nivel general de competencia subsidiaria de los Länder y especialmente de sus parlamentos, como consecuencia igualmente de lo establecido en el artículo 70.1 de la Ley Fundamental**. La re-

${ }^{40}$ Bundestagsdrucksache 16/3885; Bundestagsdrucksache-Sten.Ber. 16/74, pp. 7393A y ss.

${ }^{41}$ Bundesratsdrucksache 913/06 (acuerdo).

${ }^{42}$ K-Drs. 174, acuerdo de 5 de marzo de 2009; Proyecto de ley de 24 de marzo de 2009, Bundesratsdrucksache 16/12410; Bundesratsdrucksache 262/09.

* (Nota del traductor) El artículo 72 de la Ley Fundamental en su antigua redacción se expresaba en los siguientes términos: «1 .- En orden a la legislación concurrente, los Länder tienen la facultad de legislar en tanto en cuanto la Federación no haya hecho uso mediante ley de su facultad legislativa. 2.- Desde esta base, la Federación tiene la facultad de legislar cuando exista necesidad de reglamentación por ley federal en los siguientes casos: I) Cuando el asunto no pueda ser regulado convenientemente por la legislación de los Länder. II) Cuando la regulación de un asunto por ley de un Land pudiera afectar los intereses de otros Länder y los intereses generales. III) Cuando así lo requiera el mantenimiento de la unidad jurídica o económica y, sobre todo, para asegurar el mantenimiento de condiciones de vida uniformes más allá del territorio de un Land».

${ }^{43}$ B VerfGE 13, 230 (233 f.); resumen en retrospectiva en BVerfGE 106, 62 (136). Véase, también, DEGENHART, «Art. 72», en SACHS, Michael (edit.), Grundgesetz, cit., nota al margen $n .^{\circ} 54$.

${ }^{44}$ Véase, también, BVerfGE 106, 62 (136). Si bien los gobiernos de los Länder pudieron, por el contrario, participar ampliamente de la legislación de la Federación por medio del Bundesrat.

** (Nota del traductor) El artículo 70.1 de la Ley Fundamental afirma que «los Länder tienen facultad legislativa en la medida en que la presente Ley Fundamental no la confiera a la Federación». 
forma de la Ley Fundamental de 1994 intentó fortalecer las competencias de los Länder ${ }^{45}$, para lo que, dentro de la legislación concurrente, se limitó la cláusula de mínimos en el nuevo artículo 72.2 de la Ley Fundamental, dándole además carácter justiciable a través del procedimiento especial de control normativo establecido en el artículo 93.1.2a. de la Ley Fundamental ${ }^{46}$. Sin embargo, la realidad es que el alcance de la ley federal quedó en gran medida intacto, más si tenemos en cuenta que la facultad alternativa del legislador del Land, conforme a la previsión del artículo 72.3 (ahora 72.4)* y del artículo 125.a 2 de la Ley Fundamental, se ha hecho depender de disposición legislativa federal particular ${ }^{47}$, aún cuando ésta en todo caso pueda ser derogada a través de resolución del Tribunal Constitucional Federal en los términos del artículo 93.2 de la Ley Fundamental.

La nueva regulación del año 2006 se ha alejado nuevamente del objetivo de fortalecer las competencias legislativas de los Länder, a efectos de favorecer una mayor claridad en la clasificación de las responsabilidades. De conformidad con ello, la Federación ha procedido también a un fortalecimiento y ampliación de sus competencias. Así, han sido incluidas algunas materias en la legislación exclusiva de la Federación de acuerdo a lo establecido en el ar-

${ }^{45}$ Las modificaciones a favor de los Länder de títulos competenciales individuales tenían más bien un significado secundario. La ampliación de las competencias de la Federación sería consecuencia de la aparición de los puntos 25 y 26 del artículo 74.1 de la Ley Fundamental. 60 .

${ }^{46}$ STURM, «Art. 93», en SACHS, Michael (edit.), Grundgesetz, cit., nota al margen n. ${ }^{\circ}$

* (Nota del traductor) El artículo 72 de la Ley Fundamental se expresa en los siguientes términos: «1.- En orden a la legislación concurrente, los Länder tienen la facultad de legislar en tanto en cuanto la Federación no haya hecho uso mediante ley de su facultad legislativa. 2.- En las materias del artículo 74 apartado $1, n^{\circ} 4,7,11,13,15,19^{\mathrm{a}}, 20,22,25$ y 26 , la Federación tiene competencia legislativa en tanto en cuanto sea conveniente una regulación homogenea federal para todo el Estado, para la creación de condiciones de vida equivalentes en el territorio federal o el mantenimiento de la unidad jurídica o económica. 3.- (1) Cuando la Federación haga uso de su capacidad legislativa, los Länder pueden adoptar por ley regulación sobre: I. Caza (sin que llegue a extenderse a la regulación del permiso de caza); II. Protección de la naturaleza y el paisaje (sin que llegue a extenderse a la regulación de principios generales de protección de la naturaleza, las especies o del medio marino). III. Distribución del suelo. IV. La ordenación del territorio. V. El régimen hidráulico (sin que llegue a extenderse a la regulación de temas referidos a sustancias e instalaciones. VI. La admisión en la Universidad y certificados universitarios. (2) Las leyes federales entrarán en vigor a los seis meses de su promulgación, salvo que no se disponga otra cosa por aprobación del Bundesrat. En las materias del punto primero la ley posterior prevalece en la relación del Derecho federal y de los Länder. 4.- Por ley federal puede establecerse que una regulación legislativa federal que ya no sea necesaria en los términos expuestos en el apartado dos, pueda ser sustituida por la legislación de los Länder».

${ }^{47} \mathrm{La}$ falta de tal regulación perturba las posibilidades del proyecto de ley para la reforma del federalismo. Bundestagsdrucksache 16/813, p. 7. 
tículo 73 de la Ley Fundamental ${ }^{48}$, y, asimismo, se ha incluido una nueva competencia referida a la defensa frente al terrorismo en el n. ${ }^{\circ} 9$. Llegando más allá, con base en lo previsto en el artículo 74.1 de la Ley Fundamental, algunos aspectos referidos en los epígrafes $n .^{\circ} 27$ hasta el $n .{ }^{\circ} 33$, que hasta ahora eran objeto de legislación marco ${ }^{49}$, se han incluido dentro del catálogo de competencias propias de la legislación concurrente ${ }^{50}$. Como se ve, por tanto, esta normación no ha dado lugar a ninguna reducción en las competencias legislativas exclusivas de la Federación, si bien, junto a la desaparición del artículo 74.a de la Ley Fundamental, aparecerían, en las materias competenciales del artículo 74.1, una larga fila de pequeñas restricciones ${ }^{51}$.

La reforma del federalismo ha conllevado a otros cambios decisivos en los distintos tipos de legislación de la Ley Fundamental. En este contexto, se derogarían definitivamente las previsiones previstas en 1994 con relación a las competencias marco a causa de déficit (también por razones de eficiencia) ${ }^{52}$ estructural ${ }^{53}$. En su lugar se convertirían, en gran medida, como competencias plenas de la Federación y ahora solamente se dejarían íntegramente las relaciones jurídicas de prensa dentro de la legislación del Land.

Igualmente, los principios que rigen la legislación de tipo concurrente han sido reformados de modo considerable. Cabe decir que, ciertamente, la cláusula de mínimos del artículo 72.2 de la Ley Fundamental, perfilada en 1994, se había puesto en el ojo del huracán desde el momento en que el Tribunal Constitucional Federal había hecho valer su función de control restringiendo

${ }^{48}$ Lo dicho tiene validez, sobre todo, por un lado, con relación al artículo 73.1 I n. ${ }^{\circ} 3$ y 5 a de la Ley Fundamental, cuestiones sobre las que la Federación, anteriormente, sólo tenía un margen de competencia en el marco de lo establecido por el artículo $75 \mathrm{n} .^{\circ} 5 \mathrm{y} 6$ de la Ley Fundamental (antigua redacción), y, por otro lado, con relación al artículo $73.1 \mathrm{n} .^{\circ} 12$ hasta el n. ${ }^{\circ} 14$ de la Ley Fundamental, disposiciones que antes formaban parte de la legislación concurrente, en los términos del artículo 74.1 n. ${ }^{\circ} 4$.a, 10 y 11.a de la Ley Fundamental (antigua redacción).

${ }^{49}$ Lo dicho tiene validez tanto para el artículo $73.1 \mathrm{n} .{ }^{\circ} 28$ hasta el n. ${ }^{\circ} 32$ de la Ley Fundamental, como para el anterior artículo $75.1 \mathrm{n}^{\circ} 3$ y 4 de la Ley Fundamental. Por otro lado, con relación al artículo $73.1 \mathrm{n} .^{\circ} 27$ y n..$^{\circ} 33$, el fortalecimiento de competencias iría acompañado de una restricción en cuanto al contenido frente al anterior artículo $75.1 \mathrm{n} .^{\circ} 1,1$ a de la Ley Fundamental.

${ }^{50}$ Compárense, por ejemplo, el artículo 74.1. n. ${ }^{\circ} 19,20,22,24$ y 26 de la Ley Fundamental.

${ }^{51}$ Compárense, n. ${ }^{\circ} 1,3,7,7,11,17,18$ y 24.

${ }^{52}$ Exposición de motivos del Proyecto de ley de reforma, Bundestagsdrucksache 16/813, p. 8.

${ }^{53}$ Junto al artículo 75, también se suprimiría el artículo 98.3, inciso segundo de la Ley Fundamental (antigua redacción). Por otro lado, sin embargo, quedarían intactas las competencias legislativas fundamentales, conforme al artículo 109.3 y 140 de la Ley Fundamental en conexión con el artículo 138.1.2 de la Constitución de Weimar de 1919. 
el margen de maniobra de la Federación a este respecto ${ }^{54}$. De hecho, con relación a las consecuencias de esta línea de actuación, se afirma en la Exposición de motivos del Proyecto de Ley para la reforma del federalismo: «Los criterios que han sido concretados por la jurisprudencia del Tribunal Constitucional Federal también se muestran (...), en orden a las materias determinadas en el catálogo de competencias (...), como obstáculos (...), de aquellos aspectos que, según criterio conforme de la Federación y los Länder, no se requiere de un control del nivel de necesidad de la regulación legislativa federal» ${ }^{55}$. Y de conformidad con ello, sería limitada la cláusula en el ámbito del artículo 74.1, n. ${ }^{\circ}$ 4, 7, 11, 13, 15, 19.a, 20, 22, 25 y 26 de la Ley Fundamental, mientras que las demás materias del artículo 74.1 de la Ley Fundamental, a partir de ahora, se podrían regular por el legislador federal, sin necesidad de mayores exigencias materiales como en el marco de la legislación exclusiva de la Federación.

El nuevo artículo 72.3 de la Ley Fundamental abre, sin embargo, la posibilidad de los Länder de una «legislación derivada» (Abweichungsgesetzgebung $)^{56}$, por la que los Länder también pueden aprobar leyes después y en cuanto la Federación haya dictado una regulación legal ${ }^{57}$. De las seis materias que de antiguas competencias-marco han sido incluidas en el círculo de competencias plenas de la Federación, conforme al artículo 74 de la Ley Fundamental, solamente la mitad han sido integradas como competencias derivadas de los Länder, mientras que, por otro lado, las otras tres materias, quedan excluidas expresamente de una desviación y derivación a los Länder en lo que se refiere a una perfilación de los principios básicos (abweichungsfeste Kerne) de la legislación federal ${ }^{58}$. Cabe así, de conformidad con el artículo 72.3 de la Ley Fundamental, una normativa de perfilación o divergente de los Länder, y caso de que se produzca una posterior regulación de la Federación sobre la

${ }^{54}$ Primero de una forma elemental, en relación con el tema de cuidados de ancianos (B VerfGE 106, 62 [135]); después, ya con fundamentación de inconstitucionalidad (BVerfGE 110, 141 [174].). Respecto al § 143 I del Código Penal alemán (StGB), con relación a los perros de pelea, y, yendo más allá, en el contexto del grado de necesidad de la ley marco de normativa universitaria (BVerfGE 111, 226 [252], [265]; 112, 226 [242]). La implementación de la cláusula de necesidad se ha perfilado en BVerfGE 109, 190 (229); 113, 167 (197); 114, 196 (222 f.); 119, 59 (82), y de una manera más abierta en BVerfGE 112, 216 (222). Con respecto a la resolución sobre los horarios comerciales, véase BVerfGE 110, 10 (28).

${ }^{55}$ Exposición de motivos, n. ${ }^{\circ}$ 5.a, Bundestagsdrucksache 16/813, p. 11.

${ }^{56}$ Exposición de motivos del Proyecto de Ley de reforma, n. ${ }^{\circ}$ 5.b, Bundestagsdrucksache $16 / 813$. tal.

${ }^{57}$ Lo cual tiene validez también en el marco del artículo 125.b. 1.3 de la Ley Fundamen-

${ }^{58}$ Exposición de motivos del Proyecto de Ley de reforma, n. ${ }^{\circ}$ 5.b, Bundestagsdrucksache 16/813, p. 11.Véase, DEGENHART, «Art. 72», en SACHS, Michael (edit.), Grundgesetz, cit., nota al margen $n{ }^{\circ} 43$, quien habla, más bien de sectores o materias expresamente excluidas. 
misma cuestión, ésta debe cumplir, en principio, una moratoria en orden a su entrada en vigor, por lo que es factible, según el inciso tercero del precepto, la adopción de una nueva ley del Land. Y esto no supondría una revocación del Derecho precedente, sino una primacía en orden a la aplicación, de modo que la abrogación de la norma precedente podría suponer nuevamente la aplicación de la norma sustituida ${ }^{59}$.

\section{d) Necesidad de autorización de leyes federales}

Otra cuestión de interés de la reforma del federalismo estaba en reducir la necesidad de aprobación del Bundesrat con relación a las leyes federales, y que, antes de la reforma, afectaba a casi las dos terceras partes de las leyes federales ${ }^{60}$; en particular, cuando, por ejemplo, se hubieran suscitado mayorías opuestas de partidos políticos en el Bundestag y en el Bundesrat, ya que en ese tipo de situaciones se ha podido ver el peligro de un bloqueo o de realización de presión para lograr acuerdos en orden a cuestiones de pequeño calado.

Sin embargo, la profundidad de las modificaciones de la Ley Fundamental con respecto a este tema ha sido limitada y se ha concentrado en la reforma del artículo 84 de la Ley Fundamental, el cual sería considerado como el más relevante en orden al tema de requerir autorización de leyes federales ${ }^{61}$. Hay, empero, alguna cuestión referida a la necesidad de inquirir autorización que, en ciertos casos, ha sido ampliada a favor del Bundesrat a través de la reforma $^{62}$, como en el caso de leyes federales que supongan obligaciones para los Länder de tipo dinerario o asunción de costes, en los términos del artículo 104.a 4 de la Ley Fundamental en su nueva redacción.

De hecho, en cierto modo, se reincide y se perfila la necesidad de aceptación del Bundesrat para leyes federales en muchos de los casos establecidos en el artículo 84.1 de la Ley Fundamental. Ahora bien, hay que decir que el hecho del reconocimiento de la capacidad del legislador federal de intervenir en las posibilidades de normación de los Länder en cuestiones de su Administración pública y de tipo procedimental administrativo ${ }^{63}$ había sido precisamente la principal causa de que muchas veces se tuviese que instar

\footnotetext{
${ }^{59}$ DEGENHART, «Art. 72», en SACHS, Michael (edit.), Grundgesetz, cit., nota al margen $n .^{\circ} 40$.

${ }^{60}$ Véase, sobre ello, SACHS, Michael, Veröffentlichungen der Vereinigung der Deutschen Staatsrechtslehrer 58, 1999, pp. 39, 57 y 60.

${ }^{61}$ Compárese SACHS, Michael, Ibídem, pp. 39 y 61.

${ }^{62}$ Así, se encuentran nuevas cuestiones que requieren de aprobación del Bundesrat en los artículos 73.2, 74.2 (74.1. n. ${ }^{\circ}$ 27), 109.5, 143.c 4, de la Ley Fundamental.

${ }^{63}$ Para una mayor comprensión de este concepto, DITTMANN «Art. 84», en SACHS, Michael (edit.), Grundgesetz, cit., nota al margen n. ${ }^{\circ} 7$ y ss.
} 
autorización a tal efecto ${ }^{64}$, aún cuando, en realidad, sólo se debía haber hecho uso de esta alternativa en los momentos en que realmente hubiera sido necesario para eludir los siempre muy criticados bloqueos políticos sin reforma constitucional $^{65}$.

La nueva regulación pasa por esta cuestión, no obstante, sin reducir el margen de actuación de la legislación federal en orden a la Administración de los Länder, y, de hecho, han quedado intactas las competencias federales en esta materia, quedando por lo demás exonerado el legislador federal de la obligación de ratificación del Bundesrat, si bien, a la manera de forma de compensación, se ha previsto paralelamente, en ciertos casos, que, cuando el tema a tratar sea una cuestión que deba ser objeto de legislación de rango federal, quepa su tratamiento a la manera prevista para casos de «legislación derivada» (cfr. punto C). Desde esta perspectiva, como ya venía sucediendo hasta ahora, la respectiva regulación de determinación y fijación de principios es posible llevarla a cabo a través de la pertinente aquiescencia del Bundesrat, si bien solamente en casos excepcionales y por motivos especiales, de conformidad con lo que establece el artículo 84.1.5 de la Ley Fundamental. $\mathrm{Si}$, de acuerdo a la «cláusula de necesidad», antigua versión del artículo 72.2 de la Ley Fundamental, esta posibilidad es o no de carácter justiciable ${ }^{66}$, es cuestión que se sabrá con el tiempo.

\section{Tendencias en la doctrina del Tribunal Constitucional Federal desde 1999}

La cantidad de resoluciones importantes del Tribunal Constitucional federal en los últimos diez años ha sido inmensa. En la literatura científica se hace alusión a en torno cien de ellas como «resoluciones modelo» (Leitentscheidungen $)^{67}$, que, asimismo, son consideradas en los estudios científicos como material ineludible de estudio y reflexión ${ }^{68}$. Algunas, incluso, han llegado a producir situaciones políticas embarazosas, como cuando se dio la situación de la segunda Cuestión de Confianza del Canciller Schröder ${ }^{69}$, o cuando se han producido exigencias demandadas por amplios sectores de la

${ }^{64}$ Véase, principalmente, BVerfGE 37, 363 (382). En relación con los límites, véase, BVerfGE 114, 96 (224). En detalle, DITTMANN «Art. 84», en SACHS, Michael (edit.), Grundgesetz, cit., nota al margen n. ${ }^{\circ} 24$.

${ }^{65}$ En detalle, SACHS, Michael (edit.), Grundgesetz, cit., p. 61.

${ }^{66}$ Restrictivamente, por ejemplo, DITTMANN «Art. 84», en SACHS, Michael (edit.), Grundgesetz, cit., nota n. 21.

${ }^{67}$ Compárese al respecto la lista en SACHS, Michael, (edit.), Grundgesetz, cit., nota al margen n..$^{\circ} 15$;

${ }^{68}$ Esto es observable en la revista Juristische Schulung, siendo aún más evidente en los últimos diez años.

${ }^{69}$ BVerfGE 114,121 y ss. 
población, como la llamada ayuda por gastos de viaje por transporte al lugar de trabajo (Entfernungspauschale) ${ }^{70}$ o por el consumo de tabaco en bares y restaurantes para no fumadores (Nichtrauchergaststätten) ${ }^{71}$, o también cuando se ha tenido que hacer frente a situaciones de interés de otros grupos sociales menores como la posibilidad de inscripción de parejas de hecho ${ }^{72} \mathrm{o}$ de personas transexuales ${ }^{73}$. Por otro lado, como grupo aparte a resaltar, hay asimismo aún bastantes resoluciones relativas a la superación de las consecuencias de la Reunificación, sobre todo con relación a la equiparación de desigualda$\operatorname{des}^{74}$, como, por ejemplo, con relación a la situación de transición del régimen jurídico ${ }^{75}$, en particular en orden al cambio del sistema de prestación social ${ }^{76}$, y, llegando más allá, también con relación a algunos tipos de normativa especial derivada de la reunificación ${ }^{77}$.

En este punto debemos, no obstante, realizar también una referencia general a otras cuestiones relativas a la organización jurídica del Estado (Staatsorganisationsrecht) y a los derechos fundamentales, que han sido especialmente perfiladas por la jurisprudencia del Tribunal en la última década, y que se refieren sobre todo a aspectos de índole nacional, dificultades con respecto a la libertad religiosa y, particularmente, de la relación entre los conceptos de libertad y seguridad.

${ }^{70}$ BVerfGE, Neue Juristische Wochenschrift, 2009, 48 y ss.

${ }^{71}$ BVerfGE, Neue Juristische Wochenschrift, 2008, 2409 y ss.

${ }^{72}$ BVerfGE, 105, 313 (342 y ss).

${ }^{73}$ BVerfGE , 115, 1 y ss, con relación al derecho al nombre en el matrimonio; BVerfGE 116, 243 y ss, con relación a los transexuales extranjeros; BVerfGE, Neue Juristische Wochenschrift, 2008, 2409 y ss, con relación a la continuidad del matrimonio a partir de la transexualidad.

${ }^{74}$ BVerfGE 101, 239 y ss., sobre la denominada «exclusión de restitución o devolución» (Restitutionsausschluss); BVerfGE 101, 275 y ss., sobre la rehabilitación penal del preso en rebeldía; BVerfGE 102, 254 y ss., sobre la indemnización por expropiación tras la reunificación; BVerfGE 104, 74 y ss., sobre la «expropiación directa» de terrenos de alquiler; BVerfGE 112,1 , también sobre la cuestión de las expropiaciones en la zona de ocupación soviética (Sowjetische Besatzungszone).

${ }^{75}$ BVerfGE 101, 54y ss., sobre la Ley de adaptación del Derecho de obligaciones (Schuldrechtsanpassungsgesetz). Véase, también, BVerfGE 103, 310 y ss., sobre la deducción del sueldo según la antigüedad por realización de funciones en el antiguo Ministerio de Seguridad del Estado de la RDA.

${ }^{76}$ BVerfGE 102,41 y ss., sobre la diferenciación en la cuantía de rentas de víctimas de guerra; B VerfGE 104, 126 y ss., sobre la finalización de pensiones especiales; B VerfGE 11, 115 y ss., sobre la conversión de pensiones especiales y complementarias; BVerfGE 112, 368 y ss., sobre la conversión de las pensiones existentes; BVerfGE 117, 302 y ss., sobre la fuerza de validez de los actos administrativos de la RDA en el marco de los seguros de accidentes.

${ }^{77}$ B VerfGE 107, 133 y ss., sobre la rebaja de tarifas en el Este para abogados; BVerfGE 107,218 y 257, sobre la retribución de funcionarios en el Este. 


\section{Resoluciones relativas a la organización jurídica del Estado}

a) Principios estructurales del Estado

El artículo 20 de la Ley Fundamental sienta las bases de todo el orden y la organización estatal, determinando la implementación jurídica del concepto del principio democrático, sobre todo con relación a la legitimación democrática de órganos especiales a través del pueblo y en relación con áreas predeterminadas de cumplimento de obligaciones públicas ${ }^{78}$.

\section{b) Partidos políticos}

En relación a los partidos políticos la cuestión radicaba en resolver el tema de las consecuencias por irregularidad en las cuentas o en la financiación del partido $^{79}$, además se declararía la inconstitucionalidad de la discriminación de los pequeños partidos a través del llamado Drei-Lander-Quorum del parágrafo 18.IV de la Ley de Partidos ${ }^{80}$ (Parteiengesetz)* Particularmente destacado era también el caso del procedimiento para la ilegalización del Nationaldemokratischen Partei Deutschlands (NPD), en el que la solicitud de parte alegando un impedimento procesal no subsanable no pudo ser rechazada con la mayoría necesaria ${ }^{81}$. En este caso, la intervención determinante de confidentes e infiltrados policiales (V-Leuten) en los propios círculos de dirección del NPD se vería como una realidad indeclinable y, finalmente, el NPD ha continuado bajo la protección de las prerrogativas reconocidas a los partidos.

c) Órganos constitucionales

En relación con los órganos constitucionales ha sido sobre todo el Bundestag la institución que ha estado en el centro de atención. Varias cosas se

${ }^{78}$ B VerfGE 107, 59 (86), con relación a las Juntas de aguas (Wasserverbände) en Renania del Norte-Westfalia. Sobre ello, en detalle, SACHS, Michael, «Art. 20», en el mismo, Grundgesetz, cit., nota al margen n. ${ }^{\circ} 35$ y 44.

${ }^{79}$ BVerfGE 111, 54.

${ }^{80}$ BVerfGE 111, 382 (397).

* (Nota del traductor). La sentencia versa sobre las bases mínimas de igualdad en la competencia política. Según la sentencia del Tribunal Constitucional federal (BVerfGE 111,382), en vigor desde el año 2005, el parágrafo 18.IV quebrantaba este principio por cuanto establecía una distribución de fondos públicos para la financiación de partidos lesiva con el artículo 21 de la Ley Fundamental. El Drei-Länder-Quorum establecía que un partido que no hubiera logrado al menos el $0,5 \%$ de los votos emitidos en las elecciones, bien fueran al Bundestag o al Parlamento europeo, podrían acceder a la cuota de fondos públicos para su financiación cuando, al menos, hubiera llegado a un total del $1 \%$ de los votos en las últimas tres elecciones regionales, o en uno de ellos llegando al 5\%.

${ }^{81}$ BVerfGE 107, 339 (356). 
pueden reseñar en alusión a este tema. En primer lugar, respecto al sistema electoral $^{82}$, el Tribunal Constitucional Federal ha reseñado hace relativamente poco que la regulación de la Ley Federal Electoral (Bundeswahlgesetz) podía conducir a un peso del sufragio negativo y, por lo tanto, contradictorio con los principios del Derecho electoral ${ }^{83}$. Mientras la eliminación de esta deficiencia debía ser materializada tras las siguientes elecciones, se intrincó esta cuestión con la resolución sobre la inadmisibilidad de la utilización de medios electivos electrónicos ${ }^{84}$, que se pretendía plantear en orden a la elecciones al Bundestag. En segundo lugar, en relación con los derechos de los diputados ${ }^{85}$, como la revocación de la prerrogativa de inmunidad ${ }^{86}$ y las posibilidades de autorización de registro e incautación, han sido igualmente cuestiones perfiladas en el Bundestag ${ }^{87}$. La nueva normativa sobre el ejercicio de la función de diputado y sobre la obligación de publicidad y publicación del cargo se saldaría con un empate de votos ${ }^{88}$. En tercer lugar, hay que citar la revalidación de los derechos de los partidos minoritarios para casos de presentación y registro de pruebas en comisiones de investigación ${ }^{89}$.

Los temas del Presidente de la República Federal (Bundespräsident) y el Gobierno Federal (Bundesregierung), como cuestiones aparte, han sido aspectos raramente tratados por el Tribunal Constitucional Federal. Después de la cuestión de confianza al Canciller Federal Schröder y la subsiguiente disolución del Bundestag, el Tribunal Constitucional decidió -como cuando la cuestión de confianza al Canciller Kohl ${ }^{90}$, , que se exigieran ciertos requisitos de carácter material ${ }^{91}$, si bien, sin embargo, sin hacer excepción alguna en lo que se refiere a cuestiones de control ${ }^{92}$. Pero, por otra parte, el Tribunal ha actuado de un modo dispar y ralo en el caso del Bundesrat. Este caso llamaba

\footnotetext{
${ }^{82}$ Véase, además, frente a la cláusula del 5\% de las elecciones municipales, BVerfGE 120 , 82 (Con relación a Schleswig-Holstein).

${ }^{83}$ BVerfGE, Neue Zeitschrift für Verwaltungsrecht 2008, BvC 3, 4/07.

${ }^{84}$ BVerfGE, resolución de 3 de marzo de 2009, 2 BvC 3, 4/07.

${ }^{85}$ Aparte, en relación al procedimiento por conflicto entre órganos de los Lander (Turingia), resolvió sobre la admisibilidad limitada de la asignación de funciones extras para los diputados de un Landtag (BVerfGE 102, 224.

${ }^{86}$ BVerfGE 104, 310 (325 y ss, 331 y ss).

${ }^{87}$ BVerfGE 108, 251 (268 y ss). Sobre el complejo tratamiento de esta cuestión con relación al recurso de amparo (Verfassungsbeschwerde), véase SACHS, Michael, Juristische Schulung, 2004, 71 (72).

${ }^{88}$ BVerfGE 118, 277 (323 y ss, 352 y ss), con referencia también de la opinión de los jueces en minoría.

${ }^{89}$ BVerfGE 105, 197 (221 y ss).

${ }^{90}$ BVerfGE 62, 1 (36).

${ }^{91}$ Cuestión que se ha criticado igualmente y con insistencia en el voto particular de LübbeWolf. BVerfGE 114, 121 (182 y ss).

${ }^{92}$ BVerfGE 114, 121 (147 y ss).
} 
la atención en tanto derivaba de si, a pesar de las posiciones encontradas entre un miembro del Gobierno del Land y el Presidente del Land (Ministerpräsidenten) en una votación, podía ser ésta dada por válida a efectos de considerar el posicionamiento en bloque del Land de Brandemburgo*. Empero, esta postura no encontraría la aprobación por parte del Tribunal Constitucional Federal $^{93}$.

\section{d) Funciones del Estado}

En relación con la legislación se han tratado sobre todo temas de distribución de competencias. Junto a las ya citadas cuestiones referidas al artículo 72.2 de la Ley Fundamental, el Tribunal Constitucional había aclarado con detalle la significación última de la regulación de la normativa federal ${ }^{94}$. En este tema cabe recordar algunas situaciones destacables. En primer lugar, hay que recordar cómo causó sensación especialmente la resolución relativa a los horarios comerciales (Ladenschluss), que posibilitaba, de conformidad con el artículo 125.a 2 de la Ley Fundamental, la continuidad del Derecho federal al respecto ${ }^{95}$. En segundo lugar, hay que recordar también que ciertamente han sido frecuentes los llamamientos del Tribunal Constitucional Federal para tratar de demarcar el alcance de materias compentenciales ${ }^{96}$. En tercer lugar, en lo que se refiere a la cuestión del procedimiento legislativo federal, hay que destacar, asimismo, que se perfilarían matices importantes relativos a las Comisiones de Mediación (Vermittlungsausschusses), las propuestas de media-

* (Nota del traductor). La sentencia (de 18 de diciembre de 2002), entre otras cuestiones, trata el tema de si, a pesar de que el artículo 51.3 de la Ley Fundamenta exige la emisión en votación de los miembros del Bundesrat representantes de un Land en forma unitaria, cabe asumir tal votación en bloque aún cuando hubiera existido discrepancia o posiciones contrarias entre los mismos representantes de un Land.

${ }^{93}$ B VerfGE 106, 310 (329 y ss) con la, al, menos plausible opinión de Osterloh y LübbeWolf, p. 337 y ss. Y de este modo se malograría la aprobación de la controvertida Ley de Inmigración (Zuwanderungsgesetz).

${ }^{94}$ Compárese BVerfGE 109, 190 (229), sobre la posibilidad de arresto preventivo, de conformidad con el Código Penal; B VerfGE 113, 348 (371), en relación a las instalaciones de telecomunicación de conformidad con el Código de Enjuiciamiento Criminal (Strafprocessordnung).

${ }^{95}$ B VerfGE 110, 10 (28).

${ }^{96}$ Véase, principalmente, BVerfGE 110, 313 (368 y ss), en relación al artículo 73.1 de la Ley Fundamental; BVerfGE 109, 190 (211 y ss), en relación al artículo 74.1.1 de la Ley Fundamental; BVerfGE 108, 186 (211 y ss), en relación al artículo 73.1.7 de la Ley Fundamental; BVerfGE 103, 197 (215 y ss), en relación al artículo 73.1.11 de la Ley Fundamental; BVerfGE 109, 96 (109); 113, 167 (195), en relación al artículo 73.1.12 de la Ley Fundamental; B VerfGE 106, 62 (104), en relación al artículo 73.1.19 de la Ley Fundamental; BVerfGE 110, 142 (170 ff.), respecto al artículo 74.I.20 de la Ley Fundamental; BVerfGE 110, 370 (384 y ss.), respecto al artículo 74.I.24 de la Ley Fundamental. 
ción (Vermittlungsvorschlags) ${ }^{97} \mathrm{y}$, asimismo, de los requisitos de constitución de la Cámara, para dar mayor cumplimiento del principio de mayoría y lograr dar un mayor reflejo del espectro político de la cámara ${ }^{98}$. En cuarto lugar, cabe señalar que sería admitida finalmente la práctica de separar las fases en orden a la tramitación de proposiciones de ley, diferenciando la parte formal material de la parte de tramitación sujeta a la aprobación del Bundesrat ${ }^{99}$. En quinto y último lugar hay que recordar el fallo respecto al artículo 80 de la Ley Fundamental, en relación a la modificación de decretos leyes ${ }^{100}$ (Rechtsverordnungen) a través de ley ${ }^{101}$.

En lo que se refiere al ámbito de la Administración, se ha producido una reiterada partición de competencias entre el Estado y los Länder ${ }^{102}$. Se puso de relieve la inconstitucionalidad de la comprensión de las asociaciones laborales como formas de administración mixta, en el denominado caso Hartz $\mathrm{IV}^{103}$, tema sobre el que, dicho sea de paso, se produjo una importante discusión hasta el punto de que las noticias en prensa finalmente paralizaron la posibilidad de una reforma constitucional al efecto. Asimismo, en el contexto de la Hacienda Pública se pueden citar las importantes decisiones referidas al Derecho constitucional presupuestario (Haushaltsverfassungsrecht) ${ }^{104}$, Derecho tributario ${ }^{105}$ y sobre las relaciones financieras del Estado federal ${ }^{106}$. (73).

${ }^{97}$ Respecto a la anterior jurisprudencia, véase, BVerfGE 101, 297 (306 y ss.); 120, 56

${ }^{98}$ BVerfGE 112, 118 (133).

${ }^{99}$ BVerfGE 105, 313 (338).

${ }^{100}$ BVerfGE 114, 196 (234 y ss).

${ }^{101}$ BVerfGE 101, 1 (41 y ss).

${ }^{102}$ Compárese, sobre todo, BVerfGE 104, 249 (264), sobre las posibilidades de la Federación en el marco de la Administración delegada; BVerfGE 110,33 (47), respecto a las posibilidades de configuración de la Adiministración federal directa; BVerfGE 102, 167 (172), respecto al artículo 90.2 de la Ley Fundamental; BVerfGE 104, 238 (247 y ss), sobre la falta de competencia de los Länder en orden al almacenamiento definitivo de residuos radioactivos; BVerfGE 108, 370 (392), respecto al monopolio postal tras la privatización; BVerfGE 113, 167 (200), respecto a las posibilidades de configuración de la organización de la Seguridad Social.

${ }^{103}$ BVerfGE 119, 331(361 y ss).

${ }^{104}$ BVerfGE 119, 96.

${ }^{105}$ Véase, por ejemplo, BVerfGE 105, 135; 108, 186; 110, 274; 113, 128; 120, 125 ; BVerfG, Neue Juristische Wochenschrift, 2009, n. ${ }^{\circ}$ 48; BVerfG, resolución de 3.2.2009, 2 BvL 54/06, Deutsches Verwaltungsblatt 2009, 375. Véase, también, en este sentido, sobre el artículo 3.1 de la Ley Fundamental, notas a pie n. ${ }^{\circ} 116$ y 117.

${ }^{106}$ Sobre la cuestión de la compensación financiera de los Länder, véase, BVerfGE 101, 158 y 116, 327; BVerfGE 116, 271. En referencia a la implementación del Derecho comunitario, así como a las posibilidades de compensación por asunción de riesgos estructurales por cobertura de seguro médico, BVerfGE 113, 157. Finalmente, respecto a las ayudas al mercado de productos agrícolas, véase, BVerfG, resolución de 14.10.2008, 1 BvF 4/05, Deutsches Verwaltungsblatt 2009, 178 y ss. 


\section{Resoluciones relativas a los derechos fundamentales}

En relación a los derechos fundamentales no se pueden dejar de apuntar ciertas significativas resoluciones, cuya riqueza solamente puede ser brevemente esbozada aquí.

\section{a) Teoría general de los derechos fundamentales}

De modo lógico, el número de fallos referidos a la dogmática de los derechos fundamentales generales es ciertamente limitado. Aquí hay que hacer referencia especialmente a las resoluciones sobre algunas situaciones de ingerencia de institutos gubernativos y, paralelamente, hay que hablar también de la cobertura legal frente a éstas ${ }^{107}$. En este sentido, es reseñable la resolución sobre la exigencia de reserva de ley para la delimitación de los derechos fundamentales (Zitiergebot) ${ }^{108}$, donde se dejaba entrever un cambio de tendencia en orden a la forma de ver la tradicional desidia institucional respecto a la implementación del artículo 19.2 de la Ley Fundamental, y que llevaría a una ampliación muy importante del efecto de protección de los derechos reconocidos a las personas jurídicas ${ }^{109}$.

\section{b) Derechos fundamentales individuales}

En las decisiones del Tribunal Constitucional Federal sobre derechos y libertades individuales se deriva un panorama muy rico de situaciones problemáticas e intereses para la garantía de los derechos fundamentales. En orden al artículo 1.1 de la Ley Fundamental, y al margen del contexto de la seguridad (vid. Punto 5), hay que destacar las resoluciones relativas a los denominados casos «Benetton» sobre publicidad lesiva a la dignidad del hombre ${ }^{110}$, la extraña decisión -concerniente al derecho al libre desarrollo de la personalidad- referida al carácter de ilícito penal del incesto entre herma$\operatorname{nos}^{111}$, la decisión sobre el carácter secreto de las pruebas de paternidad ${ }^{112}$, el

${ }^{107}$ BVerfGE 105, 252 (265), (caos Glykol) sobre el artículo 12.1 de la Ley Fundamental y BVerfGE 105, 279 (292) (caso Osho) sobre el artículo 4.1; con posterioridad, por ejemplo, BVerfGE 113, 63 (76), respecto al informe de protección constitucional de la libertad de prensa.

${ }^{108}$ BVerfGE 113, 348 (365).

${ }^{109}$ Ciertamente también de los propios organismos de radio-comunicación, en cuanto se protege el desarrollo de la actividad al servicio de la libertad de radiodifusión, y flanqueado, asimismo, por la garantía judicial del artículo 19.4 de la Ley Fundamental. Véase, al respecto, BVerfGE 107, 299 (310).

${ }^{110}$ BVerfGE 102, 347 (366); BVerfGE 107, 275 (283), donde era sopesado el alcance de la dignidad del hombre como límite de la libertad de expresión del pensamiento.

${ }^{111}$ B VerfGE 120, 224 (238 y ss).

112 BVerfGE 117, 202 (224 y ss). 
curioso fallo respecto a la imposición coactiva del trato parental ${ }^{113}$, y, finalmente, sobre las posibilidades de delimitación del artículo 10 de la Ley Fundamental en situaciones de utilización de aparatos de escucha ${ }^{114}$.

En cuanto al artículo 3.1 de la Ley Fundamental son interesantes los fallos referidos a la tributación de rentas y pensiones ${ }^{115}$, sobre la llamada ecotasa $(\ddot{O} \text { kosteuer })^{116}$ y sobre la estimación del impuesto de sucesiones ${ }^{117}$, así como, también, particularmente, la decisión referida a los cambios de la política de asilo ${ }^{118}$. En cambio, en cuanto a la igualdad de derechos entre sexos, en relación con el artículo 3.2 y 3 de la Ley Fundamental, se encuentran resoluciones que ponen ciertos reparos a la posibilidad de hacer mención explicita al sexo en la ley ${ }^{119}$; esa misma línea se detecta en el fallo relativo al cumplimiento de las penas privativas de libertad ${ }^{120}$; a veces, paralelamente, se hallan decisiones que abogan por una implementación de hecho y amplia de la igualdad de derechos entre $\operatorname{sexos}^{121}$, también en lo que se refiere a la denominada discriminación indirecta ${ }^{122}$.

Respecto al artículo 5.1 de la Ley Fundamental, aparte de las resoluciones sobre los casos «Benetton», asimismo sería importante la constatación de que, también, a veces en una simple expresión ambigua puede haber una pretensión omisional ${ }^{123}$. También hay que citar, sobre la libertad de prensa, el caso «Cicero» que recordó en cierto modo al caso «Spiegel» ${ }^{124}$, de la misma manera que el caso «Esra», referido a la libertad artística, respecto a la muy conocida resolución «Mephisto» ${ }^{125}$. Por otra parte, en cuanto a la cuestión de la libertad científica sería (solamente) aceptada la evaluación de materiales

${ }^{113}$ B VerfGE, Neue Juristische Wochenschrift, 2008, 1287 (1290).

${ }^{114}$ B VerfGE 106, 28 (35).

${ }^{115}$ B VerfGE 105, 73 (110).

${ }^{116}$ B VerfGE 110, 274 (291).

${ }^{117}$ B VerfGE 117, 1 (30).

${ }^{118}$ B VerfGE 116, 229 (237).

${ }^{119}$ BVerfGE 114, 357 (364) sobre la preferencia de los niños con madre con permiso de residencia respecto a los niños con padre en iguales circunstancias.

${ }^{120}$ Así, finalmente, BVerfG (K), Neue Juristische Wochenschrift, 2009, 661. Véanse, también, los parágrafos 80 y 142 de la Ley de ejecución de medidas privativas de libertad y de medidas de prevención y seguridad en el cumplimiento de las penas (Gesetz über den Vollzug der Freiheitsstrafe und der freiheitsentziehenden Maßregeln der Besserung und Sicherung).

${ }^{121}$ Así, B VerfGE 109, 64 (89), frente a las situaciones fácticas adversas que se producen en situaciones de contratación en caso de prestaciones obligatorias excesivas por parte del empresario en casos de maternidad. Véase, también, BVerfG (K), Neue Juristische Wochenschrift, 2007, 137 y ss., respecto a la interpretación del parágrafo 611 del Código Civil (Bürgerliches Gesetzbuch).

${ }^{122}$ BVerfGE 104, 373 (393); 97, 186 (197); BVerfGE 113, 1 (15); BVerfG, Neue Zeitschrift für Verwaltungsrecht 2008, 987 (988).

${ }^{123}$ BVerfGE 114, 317 (348). Asimismo, recuérdese el llamativo caso «Dummschwätzer», BVerfG (K), Neue Juristische Wochenschrift, 2009, 749.

${ }^{124}$ BVerfGE 117, 244 y ss, conforme a BVerfGE 20, 162 y ss.

${ }^{125}$ BVerfGE 119, 1 (20 y ss), conforme a BVerfGE 30, $173 \mathrm{ff}$. 
para la investigación científica ${ }^{126}$. En conexión con el artículo 8 de la Ley Fundamental, apareció incluso una decisión de la Sala para dirimir las diferencias entre el Tribunal Contencioso-Administrativo Superior (Oberverwaltungsgericht) de Renania del Norte-Westfalia y una de las cámaras del Tribunal Constitucional Federal en torno a la prohibición de ciertas asociaciones de carácter neonazi ${ }^{127}$. En este sentido, cabe apostillar que la limitación -ciertamente cuestionable desde un punto de vista democrático-funcionaldel concepto de libertad de reunión quizás dé de que hablar a la larga ${ }^{128}$.

Asimismo, se encuentran resoluciones reseñables respecto al artículo 6 de la Ley Fundamental, referidas a la protección del matrimonio y la familia en el Derecho fiscal (de conformidad con el propio artículo 6.1 de la Ley Fundamental) ${ }^{129}$, los derechos parentales del padre de un hijo nacido extramatrimonial (de acuerdo a lo establecido en el artículo 6.2 de la Ley Fundamental) ${ }^{130}$, la obligación del empresario respecto de la paga por maternidad (de acuerdo al artículo 6.4) (31 $^{13}$, y respecto a la asignación asistencial para niños nacidos fuera del matrimonio (de acuerdo al artículo 6.5 de la Ley Fundamental) ${ }^{132}$. En relación con el artículo 7 de la Ley Fundamental, por otra parte, cabe decir que lo más destacado es el caso referido al acuerdo sobre la asignatura escolar denominada «Concepciones y formas de comprensión ético-religiosas» (Lebensgestaltung-Ethik-Religionskunde) en Brandeburgo ${ }^{133}$.

Dentro del contexto económico básico del artículo 9.3 de la Ley Fundamental hay que citar el fallo relativo al derecho a la negociación colectiva laboral ${ }^{134}$. Por otra parte, respecto a las muchas resoluciones sobre el artículo 12.1 de la Ley Fundamental ${ }^{135}$, han sido notables las decisiones referidas a

\footnotetext{
${ }^{126}$ BVerfGE 111, 333 (358).

${ }^{127}$ Compárese B VerfGE 111, 147 (154). Véase así, por ejemplo, HÖFLING, «Art. 8», en SACHS, Michael (edit.), Grundgesetz, cit., nota al margen n. ${ }^{\circ}$ 59.b.

${ }^{128}$ BVerfGE 104, 92 (104); también, nuevamente, BVerfGE 111, 147 (154). Por el contrario, más en detalle, SACHS, Michael, en STERN, Klaus, Das Staatsrecht..., cit., pp. 1204 y ss. Con referencias adicionales.

${ }^{129}$ BVerfGE 108, 351 (363 y ss.); 112, 268 (279 y ss.).

${ }^{130}$ BVerfGE 107, 150 (168 y ss.); 108, 82 (99 y ss.).

${ }^{131}$ BVerfGE 109, 64 (84 y ss.).

${ }^{132}$ BVerfGE 118, 45 (62 y ss.).

${ }^{133}$ Véase la propuesta de acuerdo en BVerfGE 104, 305. En relación a la tramitación, véase, BVerfGE 106, 210.

${ }^{134}$ BVerfGE 116, 202 (217 y ss.). Véase, también, la regulación de algunas cuestiones tocantes a este tema en la denominada Ley de Vacaciones (Urlaubsgesetz), BVerfGE 103, 293 (304 y ss.).

${ }^{135}$ Véase, además, por ejemplo, B VerfGE 101,312 y ss. (§ 13 del Reglamento profesional de la abogacía [Berufsordnung der Rechtsantwälte] de 10 de diciembre de 1996); BVerfGE 102, 264 y ss (Producción de células madre); BVerfGE 103, 1 y ss. (Habilitación para el ejercicio de la abogacía); BVerfGE 103, 72 (límite de edad y requisitos de admisibilidad para médicos dentro del servicio de la Seguridad Social); BVerfGE 107, 186 (Servicio de vacunación); BVerfGE 108, 370 y ss. (Monopolio del servicio postal); BVerfGE 110, 141 (Perros de pelea); BVerfGE 115, 205 (229 y ss.) (Secretos comerciales).
} 
los juegos de azar (Glückspiels) ${ }^{136}$, al horario de apertura al público ${ }^{137}$ y a la prohibición de fumar en restaurantes ${ }^{138}$. En cuanto al artículo 14 de la Ley Fundamental, se han de citar las resoluciones sobre las posibilidades de responsabilidad por contaminación y residuos ${ }^{139}$ y sobre el deber de protección estatal de seguros de vida ${ }^{140}$.

Respecto a la inviolabilidad domiciliaria, recogida en el artículo 13.2 de la Ley Fundamental, y las medidas de privación de libertad, establecidas en el artículo 104.2 de la Ley Fundamental, el Tribunal Constitucional Federal tuvo que incidir en la facultad judicial a tales efectos, también en lo que se refiere a la necesidad de atribución competencial suficiente del tribunal ${ }^{141}$. Por otra parte, en cuanto al artículo 19.4, se aclararía, por decisión del Pleno, que la jurisprudencia no emana del poder público en sentido estricto, sino que se comprende como el fruto de una labor de revisión judicial de fallos judiciales que, en casos de lesión, posibilitan el trámite de audiencia acorde a la forma de comprensión del derecho de tutela judicial estatal ${ }^{142}$. Finalmente, también, hay que citar el fallo sobre el denominado procedimiento reservado (in camera), a través del cual se llevó a cabo una merma de la garantía de audiencia $^{143}$.

\section{Las resoluciones con efecto supranacional}

El efecto de interdependencia europea e internacional con respecto al ámbito diferenciado del Derecho nacional ha sido también una cuestión que ha tratado el orden jurisdiccional constitucional. Desde esta perspectiva, se han hecho sentir un importante número de novedosas interconexiones en las últimas décadas ${ }^{144}$.

${ }^{136}$ Sobre los casinos, véase BVerfGE 102, 197 (212 y ss), y sobre apuestas deportivas, BVerfGE 115, 276 (300).

${ }^{137}$ BVerfGE 111, 10 (28 y ss.). Sobre la situación especial de las farmacias, véase BVerfGE 104, 357 (364 y ss.).

${ }^{138}$ BVerfG, Neue Juristische Wochenschrift, 2008, 2409 (2410 y ss.).

${ }^{139}$ BVerfGE 102, 1 (14).

${ }^{140}$ BVerfGE 114,1 y 73 .

${ }^{141}$ BVerfGE 103, 142 (150 y ss.). Posteriormente, véase, BVerfG (K), Neue Juristische Wochenschrift, 2005, 1338, y BVerfGE 105, 239 (247 y ss.).

${ }^{142}$ BVerfGE 107, 395 (401 ff.).

${ }^{143}$ BVerfGE 101, 106 (124 y ss.). Respecto al procedimiento reservado (in camera), BVerfGE 115, 205 (232 y ss.).

${ }^{144}$ Véase, por ejemplo, B VerfGE 108, 238 y ss., en relación a una disposición provisional frente a la notificación de una demanda class action de los Estados Unidos de Norteamérica por daños y prejuicios. En relación al artículo 25 de la Ley Fundamental, véase, por ejemplo, BVerfGE 117, 1 41. Respecto a la renuncia de inmunidad diplomática, véase, BVerfGE 118, 124, por negación de pago por Estado insolvente (Argentina). 


\section{a) Derecho de la Unión Europea}

Con relación al Derecho comunitario ${ }^{145}$, el Tribunal Constitucional Federal ha completado la jurisprudencia iniciada en 1974 (Solange) con la decisión Bananenmarkt y ha hecho depender de estas pautas la protección de los derechos y libertades fundamentales jurídico-constitucionales frente al Derecho comunitario secundario, también a efectos de cubrir, en materia de derechos fundamentales, cierta posible laxitud en orden a la protección precisa e indispensable en el plano comunitario y europeo ${ }^{146}$. Así, en cierto modo, ha quedado cerrado, en la práctica, un conflicto con el Tribunal de Justicia de la Unión Europea ${ }^{147}$, y se ha incluido, a la vez, un control jurídico interno para prever reglas básicas adicionales a partir de ciertas directrices ${ }^{148}$. Desde esta base, por ejemplo, un recurso de amparo frente a la Ley sobre la orden europea de detención y entrega fue admitido por el propio Tribunal Constitucional, sin grandes dosis de fundamentos y aun versando sobre una Decisión Marco del Consejo de la Unión Europea*, por cuanto la normativa no preservaba suficientemente los márgenes internos y no tanto en el hecho de que el legislador nacional tenga reconocida capacidad de, en un momento dado, denegar una solicitud de entrega formulada por una autoridad judicial de un Estado miembro ${ }^{149}$.

${ }^{145}$ Para una comparación respecto a los límites de este fenómeno en los últimos diez años, también en el Derecho comunitario, véase, por ejemplo, BVerfGE 104, 214 (216) (frente a una propuesta del Tribunal de Justicia de la Unión Europea en el procedimiento de prohibición de partidos referido al Nationaldemokratische Partei Deutschland).

${ }^{146}$ BVerfGE 102, 147 (161 y ss.).

${ }^{147}$ Véase STREINZ, «Art.23», en SACHS, Michael (edit.), Grundgesetz, cit., nota al margen $n .^{\circ} 41$.

${ }^{148}$ BVerfGE 118, 79 (95 y ss.); BVerfG (K), Neue Juristische Wochenschrift, 2007, 3628 (3629). Respecto a las bases especiales para la promulgación de decretos provisionales en ciertos casos, véase BVerfG, Neue Zeitschrift für Verwaltungsrecht 2008, 543. Téngase, asimismo, en cuenta la resolución B VerfGE 116, 202 (214), que autoriza el control normativo judicial conforme al artículo 100.1 de la Ley Fundamental también en relación (de forma complementaria) a la normativa emanada del marco jurídico europeo que pueda ser contradictoria respecto a la Ley Fundamental. Véanse, por otro lado, B VerfGE 110, 141 (155); BVerfGE 114, 196 (220).

* (Nota del traductor). La problemática derivaba de la propia Ley Fundamental, que reconocía en su artículo 16.2 que «ningún alemán puede ser entregado al extranjero». Así, ante la nueva realidad europea, se debía proceder a una reforma del artículo. Aún así, la reforma fue rala y simplemente se limitó a introducir una cláusula que advertía que por ley se podría adoptar una regulación divergente en estos casos para situaciones de extradición a un Estado de la Unión Europea o a un Tribunal Internacional, siempre y cuando se respeten los principios del Estado de Derecho.

${ }^{149}$ BVerfGE 113, 273 (292, 301). Sobre ello, véase STREINZ, «Art. 23», en SACHS, Michael (edit.), Grundgesetz, cit., nota al margen n. ${ }^{\circ} 41$ (con más referencias). 


\section{b) El Convenio Europeo de los Derechos Humanos}

Con relación al Convenio Europeo de Derechos Humanos ${ }^{150}$ hay que decir que ha supuesto ciertas desavenencias entre el Tribunal Europeo de Derechos Humanos y el Tribunal Constitucional, particularmente en cuestiones de libertad de prensa y derecho al libre desarrollo de la personalidad ${ }^{151}$. Empero, después de que el Tribunal Europeo de Derechos Humanos ${ }^{152}$ hubo reprochado al Tribunal Constitucional Federal ${ }^{153}$ el hecho de ser condescendiente con una decisión del Tribunal Supremo Federal ${ }^{154}$ lesiva del artículo 8 del Convenio ${ }^{155}$, los mencionados órganos han aceptado las pautas del Tribunal Europeo de Derechos Humanos y se han entendido también como un refuerzo incluso para la interpretación de los derechos fundamentales de la Ley Fundamental ${ }^{156}$. Así, el Tribunal Constitucional, desde la decisión Görgülü ha quedado de nuevo ligado a esta línea fundamental, atribuyéndose a las garantías del Convenio Europeo de Derechos Humanos y a las resoluciones del Tribunal Europeo de Derechos Humanos una significación notable también a nivel nacional.

\section{c) Intervenciones militares en el extranjero}

La progresiva participación de la Bundeswehr en operaciones en el extranjero ha supuesto el desarrollo de ciertas pautas ${ }^{157}$. En principio, las misiones militares en el exterior por razones de defensa son posibles, en el marco del artículo 24.II de la Ley Fundamental, si bien requieren de la aprobación del Bundestag, a pesar de no requerir forma de ley ${ }^{158}$. En este sentido, el Tri-

${ }^{150}$ El Tribunal Constitucional Federal hace referencia al mismo cuando así lo ha considerado oportuno. Así, por ejemplo, véase BVerfGE 103, 44 (64); 107, 339 (394); 107, 395 (408 y ss.); 108, 282 (311); 110, 226 (253); 110, 339 (342); 119, 181 (211).

${ }^{151}$ STEDH, Neue Juristische Wochenschrift, 2004, 2467.

${ }^{152}$ BVerfGE 101, $361(379,391)$.

${ }^{153}$ BGHZ 131, 332 .

${ }^{154}$ Compárese, a este respecto, METZ, «Das Recht Prominenter am eigenen Bild in Kollision mit Drittinteressen», 2008.

${ }^{155}$ BGH, Neue Juristische Wochenschrift, 2007, 1977, nota al margen n. ${ }^{\circ} 12$; BVerfGE 120, 180 (199). Referido a los casos en los que la Princesa Carolina de Hannover, a través de su recurso de amparo, no tuvo ningún éxito.

${ }^{156}$ B VerfGE 111, 307 (315). En relación con algunas consecuencias de esta línea, véase, BVerfG (K), Neue Juristische Wochenschrift, 2005, 1105; 1765; 2685.

${ }^{157}$ B VerfGE 90, 286 (Con relación a la intervención en Somalia).

${ }^{158}$ En tono crítico respecto a la falta de ley formal, teniendo en cuenta la doctrina, STREINZ, «Art. 24», en SACHS, Michael (edit.), Grundgesetz, cit., nota al margen n. ${ }^{\circ}$ 76.a); KOKOTT, «Art. 87», en SACHS, Michael (edit.), Grundgesetz, cit., nota al margen n. ${ }^{\circ} 38$ ). Sobre ello, véase, también, SACHS, Veröffentlichungen der Vereinigung der Deutschen Staatsrechtslehrer, 58 (1999), p. 39 (71). Respecto al procedimiento, caso de autorización, véase la Ley reguladora de la intervención del Parlamento en este tipo de situaciones (Parlamentsbeteiligungsgesetz) de 18.3.2005, BGB1 I, 775. 
bunal Constitucional Federal ha precisado el desarrollo de este tipo de colaboraciones con la OTAN (de forma ciertamente amplia) en el marco de la Organización del Tratado del Atlántico Norte y de los distintos fines de la Alianza de conformidad con el artículo 24.2 de la Ley Fundamental ${ }^{159}$. Estos límites se percibieron particularmente en el marco de la misión ISAF en Afganistán ${ }^{160}$, como también en el hecho de las objeciones a la participación de soldados alemanes en aviones de control y vigilancia aérea (AWACS) de la OTAN en la Guerra de Irak ${ }^{161}$.

\section{d) Problemas migratorios y cuestiones en relación a la extradición}

En relación con la emigración, hay que señalar el buen criterio del Tribunal Constitucional en el fallo sobre la dación de vivienda en casos de emigrantes de origen alemán provenientes de los Estados del este de Europa (Späutaussiedlern), sobre la base del artículo 1.1 de la Ley Fundamental ${ }^{162}$. Además, sería aceptada la posibilidad de suspensión de naturalización en casos de obtención de ésta bajo cobertura del artículo 16.1 de la norma constitucional pero de forma fraudulenta, de acuerdo al parágrafo 48 de la Ley de Procedimiento Administrativo (Verwaltungsverfahrensgesetz) ${ }^{163}$.

Por otra parte, el Tribunal Constitucional Federal, en algunas ocasiones, ha determinado que la sujeción a las reglas generales de Derecho internacional, de conformidad con el artículo 25 de la Ley Fundamental, no impide la extradición de extranjeros, aun cuando sea posible que en el Estado solicitante se puedan cometer ciertas lesiones de derechos fundamentales ${ }^{164} \mathrm{o}$ cuando hayan sido reclamados a Alemania con artimañas ${ }^{165}$.

\section{Los problemas con la libertad religiosa}

Después de que el Tribunal Constitucional Federal reconociera carácter corporativo a los Testigos de Jehová, como comunidad religiosa, los cuales siempre habían tenido en Alemania una posición marginal, ${ }^{166}$ surgió la cues-

${ }^{159}$ BVerfGE 104, $127(199,212)$ (sobre el concepto estratégico de la OTAN de 1999).

${ }^{160}$ BVerfGE 118, 244 (262 y ss.).

${ }^{161}$ BVerfGE, Neue Juristische Wochenschrift, 2008, 2018 (2020).

${ }^{162}$ BVerfGE 110, 177 (190 y ss.).

${ }^{163}$ BVerfGE 116, 24 (36 y ss.).

${ }^{164}$ BVerfGE 108, 129 (136), especialmente véase en este fallo el voto discrepante de M. SOMMER y LÜBBE-WOLF (con relación a las condiciones de detención). Véase, igualmente, BVerfGE 113, 154 (164), en relación con una pena de cadena perpetua sin medidas de revisión judicial de la pena.

${ }^{165}$ BVerfGE 109, 13.

${ }^{166}$ BVerfGE 102, 370 (384 y ss.). Con relación a la confirmación de la cuestión, véase, BVerwG, Neue Juristische Wochenschrift, 2006, 3156. 
tión nuevamente pero esta vez con referencia a grupos de corte islámico. En este caso, igualmente, había reivindicaciones de trasfondo religioso a resolver por el Tribunal Constitucional, pero incardinadas a la necesidad de proteger a la vez la libertad de disidencia ante las posiciones de la mayoría*.

También aquí destaca el fallo relativo a la prohibición de degollar un animal conforme al rito judío e islámico (Schächtverbot). El Tribunal Constitucional Federal determinó -poco antes de la recepción del concepto de protección animal del artículo 20.a de la Ley Fundamental- una autorización especial para casos de matarifes extranjeros por medio de una interpretación conforme a la Constitución de la norma aplicable al caso, combinando, de forma ciertamente original, varios conceptos fundamentales: por un lado, la libre elección de profesión, del artículo 2.1 de la Ley Fundamental, en relación a las personas que trabajan en un matadero; por otro, el principio de proporcionalidad y el artículo 4.1 de la Ley Fundamental, por cuanto al matarife recurre un determinado tipo de cliente precisamente por la forma religiosa en la que procede al sacrificio del animal y el tratamiento de la carne ${ }^{167}$.

Poco después de diez años desde el caso del crucifijo en la escuela pública $^{168}$, apareció el segundo elemento de discordia principal de la década en el ámbito religioso, esta vez por un trozo de tela, a saber, el tradicional pañuelo de la cabeza (Kopftuch), en particular de una profesora ${ }^{169}$. En este caso, la solicitante había renunciado la contratación de dar sus clases ya que ella había pensado que podía proseguir cumpliendo con el precepto religioso de usar el tradicional pañuelo, también durante el horario lectivo, sin lugar a mayores complicaciones. El Tribunal Constitucional Federal eludió, haciendo hincapié en el hecho de ausencia de ley al efecto, una apreciación concluyente sobre el fondo de la cuestión, a pesar de lo cual contuvo un número de votos particulares bastante duros ${ }^{170}$. Así las cosas, se conminó al legislador del Land competente, sobrepasando en cierto modo las exigencias del artículo 4 de la Ley Fundamental, a hacer efectivo el «mandato estricto de tratamiento ecuá-

* (Nota del traductor). El Tribunal Constitucional Federal ha entendido que los ciudadanos seguidores de una fe minoritaria no están obligados a compartir los valores constitucionales de la mayoría (BVerfGE 102, 370) en cuanto no suponga la afectación de derechos de terceros. Sobre esa base, el Tribunal Constitucional alemán ha afirmado posteriormente, por ejemplo, que no se debe discriminar a una cajera de un supermercado por llevar el velo (BVerfGE, 1BvR 792/03, de 30 de julio de 2003).

${ }^{167}$ BVerfGE 104, 337 (345 y ss.).

${ }^{168}$ BVerfGE 93, 1 (15).

${ }^{169}$ Antes, por ejemplo, el Tribunal Constitucional Federal había tenido que corregir a un Juez de Menores, que en su Sala había prohibido, de forma general, llevar el pañuelo por motivos religiosos ( BVerfG (K), Neue Juristische Wochenschrift, 2007, pp. 56 y ss. Respecto a otros casos, también en el extranjero, y sobre la problemática en general, véase, KOKOTT, «Art. 4», en SACHS. M., (edit.), Grundgesetz, cit., notas al margen n. ${ }^{\circ} 59$ y 72.

170 BVerfGE 108, $282(297,306)$. Votos divergentes de los jueces Jentsch, Di Fabio y Mellinghoff, pp. 314 y ss. 
nime de los distintos credos». Así las cosas, y teniendo en cuenta las diversas tentativas del legislador para posibilitar a la par un tratamiento especial en orden a los símbolos cristianos, todo parece indicar que este tema será una cuestión jurídico constitucional pendiente también en el séptimo decenio de la Ley Fundamental ${ }^{171}$

Por último, cabe citar aquí también la decisión de la Sala ${ }^{172}$ que ratificaba el fallo del Tribunal Contencioso Administrativo Federal (Bundesverwaltungsgericht) de disolución de una agrupación religiosa islámica (Kalifatsstaats $)^{173}$. Dicha prohibición había sido determinada por el Ministerio de Interior (Bundesministerium des Innern) desde que, ya a finales de 2001, se había suspendido la imposibilidad de prohibición de agrupaciones de tipo religiosos (Religionsprivilegs), cara a refrenar la progresiva implantación por la fuerza de una autoridad paralela al Estado y de corte islámico en Alemania. Los fallos relacionados con esta cuestión han dado lugar, además, a un último grupo aparte de resoluciones del Tribunal Constitucional Federal que versan sobre cuestiones de libertad y seguridad.

\section{Libertad y seguridad}

Incluso con anterioridad al 11 de septiembre de 2001 y más allá del tema de la lucha contra el terrorismo ${ }^{174}$, cabe decir que una de las notas identificativas de la última década ha sido el estudio de la interrelación de equilibrio entre los conceptos de libertad y seguridad. Empero, hay que reconocer que estos sucesos han propiciado un mayor interés por estos temas. En este sentido y en orden a las nuevas necesidades de seguridad, el Tribunal Constitucional Federal ${ }^{175}$ ha tenido que filtrar el excesivo acervo normativo federal y de los distintos Länder sobre esta materia -también derivado de la regulación

${ }^{171}$ B VerwGE 121, 140. Y lo mismo cabe decir con relación al problema tampoco solucionado de la enseñanza religiosa mahometana en las escuelas estatales. Véase, por ejemplo, BVerwGE 123, 49.

${ }^{172}$ BVerfG (K), Neue Juristische Wochenschrift, 2004, pp. 47 y ss.

${ }^{173}$ BVerwG, Neue Zeitschrift für Verwaltungsrecht, 2003, pp. 986 y ss.

${ }^{174}$ Recuérdese, por ejemplo, los enfrentamientos estudiantiles y la actuación terrorista de la Fracción del Ejército Rojo (Rote Armee Fraktion o banda Baader-Meinhof), las medidas de seguridad de 1972, así como su reorganización. Sobre ello, H. HOFMANN, en ISENSEE / KIRCHHOF (coord..), Handbuch des deutschen Staatsrechts, I, 3, Edic. 2003, § 9, nota al margen n. 59 y ss.

${ }^{175}$ Compárese, principalmente, en razón a la peligrosidad del delincuente (si bien teniendo en cuenta cautelas en orden al principio de proporcionalidad), ciertas reglamentaciones admitidas para la detención preventiva sin límite temporal (BVerfGE 109, 133 [149]). Véase, también, BVerfGE 109, 120 (235), en razón a la sobreaplicación por falta de competencia de la normativa sobre internamientos de los Länder; BverfG (K) Neue Juristische Wochenschrift, 2009, pp. 980 y ss, y BVerfGE 117, 71 (87) en orden a la revocación de decisiones judiciales y posibilidades de ejecución de la cadena perpetua. 
de los distintos progresos técnico-científicos-, que se había gestado durante diez años desde el fin del concepto de seguridad del Estado de la República Democrática alemana (RDA) y que pecaba en repetidas ocasiones de cierto exceso de celo, en tanto que lesionaba en muchos casos tanto los derechos fundamentales contenidos en los artículos 10 y 13 de la Ley Fundamental, como el derecho al libre desarrollo de la personalidad en relación con el principio de autodeterminación informativa ${ }^{176}$.

Esta serie de resoluciones se inicia con el fallo sobre el control informático de datos del Servicio de Inteligencia Federal (Bundesnachrichtendienst) ${ }^{177}$ y que culminó con la denominada «vigilancia secreta de gran escala» (Grossen Lauschangriff), todo lo cual, teniendo en cuenta los límites del artículo 13.3 de la Ley Fundamental (bajo interpretación ajustada) y el hecho de que las disposiciones de la Ley de Enjuiciamiento Criminal no han sido aceptadas ${ }^{178}$, ha encontrado una respuesta provisional, por una parte, con el fallo frente a la posibilidad de infiltración por sistemas técnicos informáticos tras la Ley del Land Renania del Norte-Wesfalia de Protección de la Constitución (Verfassungsschutzgesetz) ${ }^{179}$, que daría lugar al derecho fundamental a la confidencialidad de los datos que se tengan en un ordenador personal ${ }^{180}, \mathrm{y}$, por otra parte, con el fallo frente a la posibilidad automatizada de registro de matrículas de automóvil ${ }^{181}$. Así, y mientras la nueva regulación de la Ley de Enjuiciamiento Criminal (Strafprozessordnung) ${ }^{182}$ probaba su eficacia, el Tribunal Constitucional debía además tener bajo control a las autoridades y a los órganos jurisdiccionales en su labor de aplicación de la ley, para evitar un excesivo celo de la policía en situaciones de examen informático de datos con fines preventivos ${ }^{183}$, en la utilización y registro digital de huellas y pruebas ge-

${ }^{176}$ Véase, también, si bien en otro contexto, BVerfGE 118, 168 (183 y ss.), en relación con la cuestión de almacenamiento automatizado de datos; BVerfGE 120, 351 (359 y ss.), en relación con la recopilación de datos sobre relaciones tributarias en el extranjero.

${ }^{177}$ BVerfGE 100, 313. Con base en defectos competenciales, pero también por razones de indeterminación y desproporcionalidad de las disposiciones sobre vigilancia de las telecomunicaciones en Baja Sajonia en BVerfGE 113, 348 (364 y ss.). Sólo bajo presupuestos ajustados se admitiría la aplicación del GPS conforme al $§ 100 \mathrm{c} \mathrm{I} \mathrm{n.} 1$ lit. b de la Ley de Enjuiciamiento Criminal (Strafprozessordnung) en in BVerfGE 112, 304 (315).

${ }^{178}$ BVerfGE 109, 279.

${ }^{179}$ BVerfGE 120, 274 (302 y ss.).

${ }^{180} \mathrm{Al}$ respecto, escépticamente, con más detalles, SACHS / KRINGS, Juristische Schulung, 2008, 481 y ss.

${ }^{181}$ BVerfGE 120, 378 (397) con referencia a las normas de Hesse y Schleswig-Holstein.

${ }^{182}$ Sobre ello, compárese, (si bien la petición sólo fue admitida en parte), sobre la acción precautoria, BVerfG, Neue Zeitschrift für Verwaltungsrecht 2008, pp. 543 y ss.; BVerfG, Neue Zeitschrift für Verwaltungsrecht 2009, pp. 96 y ss. Por otro lado, con carácter negativo BVerfG, Neue Zeitschrift für Verwaltungsrecht 2009, pp. 103 y ss.

${ }^{183}$ BVerfGE 115, 320 (341). 
néticas ${ }^{184}$, como también en su labor de manejo y almacenamiento de información en soporte informático ${ }^{185}$.

El fallo sobre la Ley Federal de Seguridad Aérea (Luftsicherheitsgesetz), que habilitaba a la Bundeswehr a derribar un avión capturado por terroristas, cuando sólo de ese modo se pudiera evitar la utilización de la máquina para realizar un atentado, suponía, por otro lado, algo más que dirimir entre un conflicto entre libertad y seguridad, sobre todo porque giraba no «sólo» en torno al derecho de libre desarrollo de la personalidad inmaterial, sino, más allá, al derecho fundamental a la vida mismo. En este sentido, el Tribunal Constitucional Federal habló del derecho fundamental a la vida también aquí como «base vital de la dignidad del hombre», incluyendo en este caso -con relación (sólo) a los pasajeros inocentes- el artículo 1.1 de la Ley Fundamental. Empero, el Tribunal no consiguió ser totalmente convincente en la resolución en la aplicación de la denominada «formula objeto» ${ }^{186}$.

\section{Conclusión}

Queda patente que se ha ido desplegando la realidad normativa de la Ley Fundamental desde 1949, sobre todo en relación con la reforma del federalismo y en relación con los resultados derivados de los desarrollos del orden supranacional; y en estas dos direcciones es muy probable que este desarrollo continúe. Y lo mismo se puede esperar en orden a los puntos básicos de la judicatura constitucional de las últimas décadas. Seguramente el Tribunal Constitucional Federal tendrá que hacer de nuevo frente en el futuro a temas como la perfilación de los desarrollos supranacionales, las cuestiones de tipo religioso con relación al Islam y su integración con la forma constitucional de comprensión del fenómeno religioso, así como al problema de conjugación de los conceptos de libertad y seguridad a la luz de las novedosas amenazas y las posibilidades de defensa ${ }^{187}$. También, por otra parte, cabe pronosticar otro tipo de dificultades, por ejemplo, derivadas de las consecuencias de la actual crisis financiera ${ }^{188}$, si bien, desde un prisma estricto de Derecho constitucional este punto excede del marco de esta digresión retrospectiva ${ }^{189}$. La experien-

${ }^{184}$ BVerfGE 103, 21 (35).

${ }^{185}$ BVerfGE 113, 29 (44), con relación a un bufete de abogados, y BVerfGE 115, 166 (181) con relación a una juez.

${ }^{186}$ BVerfGE 115, 118 (151 y ss., 157). Sobre ello, MURSWIEK, «Art. 2», en SACHS. M., (edit.), Grundgesetz, cit., notas al margen n. 182 a, y HÖFLING, «Art. 1», Ibídem, nota al margen $n .^{\circ} 22$, con más referencias.

${ }^{187}$ Respecto al recurso frente al Tratado de Lisboa sería discutido ya del 10 al 11 de febrero de 2009.

${ }^{188}$ Compárese la decisión del 17 de febrero de 2009.

${ }^{189}$ El recurso frente a la Ley de estabilización del mercado financiero (Finanzmarktstabilisierungsgesetz) ha sido rechazado por el Tribunal Constitucional (BVerfG K decisión del 26 de marzo de 2009, 1 BvR 119/09). 
cia de los últimos sesenta años permite que tengamos la esperanza de que, a través de la alternativa de reforma del texto constitucional y la jurisprudencia del Tribunal Constitucional Federal, realmente haya bastantes posibilidades como para decir que también la Ley Fundamental está asegurada hasta su próximo aniversario como Constitución exitosa y eficaz. 